\title{
Dengue Fever and COVID-19 Co-Infection at the Emergency Department of a Tertiary Care Hospital in Jeddah, Saudi Arabia
}

\author{
Abdalla Khali ${ }^{1,2}$, Badr Badr $^{1}$, Harry Wright $^{2}$, Mohammed Talo $^{1}$, Mohammad Atteiya $^{1}$ \\ ${ }^{1}$ International Medical Centre Hospital, Jeddah, Saudi Arabia \\ ${ }^{2}$ King's College trust PRUH, London, UK
}

Received: 20/11/2020

Accepted: $24 / 11 / 2020$

Published: $28 / 12 / 2020$

How to cite this article: Khalil A, Badr B, Wright H, Talo M, Atteya M. Dengue fever and COVID-19 co-infecton at the emergency department of a tertiary care hospital in Jeddah, Saudi Arabia. EJCRIM 2020;7: doi:10.12890/2020_002167.

Conflicts of Interests: The Authors declare that there are no competing interests.

This article is licensed under a Commons Attribution Non-Commercial 4.0 License

\section{ABSTRACT}

Introduction: Co-infection with COVID-19 and other viral or bacterial infections has been described in many studies. Most cases of dengue fever in Saudi Arabia have been reported in Jeddah city and mainly during the summer season.

Method and results: We describe four patients who presented to the emergency department with febrile illness accompanied by symptoms and blood tests suggestive of dengue fever. They also had radiological findings suggestive of COVID-19 chest infection and positive PCR tests. Three of the patients required hospital admission, and all had a good outcome.

Conclusion: In areas with a high rate of dengue fever, serological screening for dengue fever should be considered as part of COVID-19 investigation, especially if symptoms or a full blood count are suggestive.

\section{LEARNING POINTS}

- Dengue fever (DF) and COVID-19 co-infection has been reported in countries with a high rate of DF.

- Symptoms and /or full blood count changes suggestive of DF should draw the attention for a DF screening while reviewing patients with suspected COVID-19 infection.

\section{KEYWORDS}

Dengue fever, COVID-19 infection, thrombocytopenia, clinical outcome

\section{INTRODUCTION}

A meta-analysis of 30 studies including 3,834 patients showed 7\% of hospitalized COVID-19 patients had a bacterial co-infection, with a higher proportion of such cases among ICU patients. The most common bacteria were Mycoplasma pneumoniae, Pseudomonas aeruginosa and Haemophilus influenzae. The pooled percentage of viral co-infection was 3\% (respiratory syncytial virus and influenza A were the most common viruses) ${ }^{[1]}$. Although Saudi Arabia is not one of the Asian dengue fever (DF) belt countries, 6,345 patients with DF were reported in 2018 , of whom 4,942 were in Jeddah city ${ }^{[2,3]}$. We describe four patients who visited the emergency department (ED) with febrile illness during August 2020 and were found to have DF and COVID-19 co-infection. None of the patients had travelled outside Jeddah city in the previous 6 months. 


\section{CASE DESCRIPTIONS}

\section{Case 1}

A 63-year-old Saudi man presented to the ED with a 4-day history of fever, headache, sore throat and myalgia. He had no nausea, vomiting or respiratory complaints. He had diabetes mellitus type 2 and a single left kidney. His temperature was $38.2^{\circ} \mathrm{C}$. The rest of his vital signs including oxygen saturation were within normal limits. The patient looked sick with dry mucous membranes. He had no signs of meningeal irritation and the rest of his physical examination was unremarkable. Blood test results are given in Table 1 and his chest $x$-ray is shown in Fig. 1a. He had a positive COVID-19 PCR test (nasopharyngeal swab) and was admitted to the isolation unit. He developed a dry cough, wheezing and vomiting. His oxygen saturation was around $92 \%$ in room air. He received oxygen via a nasal cannula, IV paracetamol, a $0.9 \%$ sodium chloride fluid infusion, ondansetron, budesonide and nebulized salbutamol. His renal function improved, his fever and headache resolved, and he was discharged home 6 days after admission.

\section{Case 2}

A 53-year-old female patient presented to the ED with a 3-day history of fever, nausea, vomiting and watery diarrhoea. She denied any respiratory symptoms or loss of smell or taste. She had a history of mild bronchial asthma. Her temperature was $37.8^{\circ} \mathrm{C}$. Her other vital signs and oxygen saturation were normal. She was dehydrated but the rest of her physical examination was unremarkable. Stool analysis was negative. She received IV fluids and an antiemetic, and was prescribed oral antipyretics and an antiemetic. She was discharged to home isolation and was followed by the infection control team. However, 4 days later, she presented to the ED with persistent fever, shortness of breath, epigastric pain and poor oral intake. Her main blood test results are displayed in Table 1. The other blood investigations and an $\mathrm{x}$-ray of the abdomen were normal. Her chest x-ray is shown in Fig. 1b. She was admitted to the isolation ward where she received IV paracetamol, ceftriaxone, azithromycin, dexamethasone, fluids and pantoprazole. She required oxygen via a nasal cannula. Her fever subsided after the third day and she did not require further oxygen. She was discharged on the fifth day after admission.

\section{Case 3}

A 48-year-old woman presented to the ED with a 5-day history of fever, cough and shortness of breath. She had been reviewed at a polyclinic 3 days earlier, diagnosed with COVID-19 infection, and prescribed azithromycin and paracetamol. She was still febrile and had developed a headache, myalgia and bone pain. She had a history of hypothyroidism. Her temperature was $39.3^{\circ} \mathrm{C}$, oxygen saturation was $93 \%$ in room air and the rest of her vital signs were normal. Chest examination revealed bilateral basal inspiratory crackles. The remainder of her physical examination was normal. Her blood test results are given in Table 1. Her chest $x$-ray is shown in Fig. 1c. She was admitted to the isolation unit and received IV dexamethasone, paracetamol, ceftriaxone and oxygen therapy. Her fever subsided, her breathing improved, and she did not require oxygen therapy. She was discharged after 4 days.

\section{Case 4}

A 46-year-old man presented to the ED with a 3-day history of fever, sore throat, dry cough, retro-orbital headache and bone pain. He had been in contact with a friend who was positive for COVID-19. His medical history was insignificant. His temperature was $38.7^{\circ} \mathrm{C}$. His other vital signs were normal. He had a congested throat with no palpable lymph nodes. The remainder of the clinical examination was unremarkable. His blood test results are given in Table 1. His chest x-ray is shown in Fig. 1d. He was discharged to self-isolation on symptomatic treatment, and was followed up by the infection control team. His symptoms improved gradually and his repeated PCR swab 2 weeks later was negative.

\section{DISCUSSION}

Most cases of dengue fever reported in Saudi Arabia have been in Jeddah city. In addition to clinical features (fever, headache, bone pain, nausea, abdominal pain and vomiting), leucopoenia and thrombocytopenia were typical for DF. Most DF cases occurred in May, June, July and August. Haemorrhagic dengue fever (HDF) was reported in $4.1 \%$ of adults and in $7.3 \%$ of children ${ }^{[4]}$. All of four patients with dengue fever and COVID-19 co-infection presented in August 2020.

Dengue virus type 1 (DENV-1) is the dominant serotype in Saudi Arabia, followed by DENV-3 ${ }^{[5]}$. In a large retrospective comparative study in Jeddah (involving 17,646 confirmed cases in the 7 years from 2010 to 2016), risk factors and predictors of severe dengue fever (SDF) were studied in adults versus children. Secondary infection was a more significant risk factor and predictor of SDF in adults than in children. Clinical fluid accumulation and neutropenia were less significant risk factors and predictors of SDF in adults than in children. Mortality rates were $8.9 \%$ and $10.7 \%$ in children and adults with SDF, respectively ${ }^{[6]}$. 


\begin{tabular}{|c|c|c|c|c|c|}
\hline & Case 1 & Case 2 & Case 3 & Case 4 & \\
\hline Sex & Male & Female & Female & Male & \\
\hline Age & 63 years & 53 years & 48 years & 46 years & \\
\hline Comorbidity & $\begin{array}{l}\text { Single kidney, } \\
\text { diabetes mellitus type } 2\end{array}$ & Asthma & Primary, hypothyroidism & & \\
\hline White cell count & $\begin{array}{l}2,730 / \mu l \\
(4,000-11,000 / \mu l)\end{array}$ & $2,920 / \mu l$ & $2,990 / \mu l$ & $2,920 / \mu l$ & \\
\hline Neutrophil count & $\begin{array}{l}1,170 / \mu l \\
(2,000-7,500 / \mu l)\end{array}$ & $1,370 / \mu l$ & $1,510 / \mu l$ & $850 / \mu l$ & \\
\hline $\begin{array}{l}\text { Absolute lymphocyte } \\
\text { count }\end{array}$ & $\begin{array}{l}1,220 / \mu l \\
(1,300-3,500 / \mu l)\end{array}$ & $1,270 / \mu l$ & $1,260 / \mu l$ & $1,740 / \mu l$ & \\
\hline Haemoglobin & $11.1 \mathrm{~g} / \mathrm{dl}(13.5-17.5 \mathrm{~g} / \mathrm{dl})$ & $14.3 \mathrm{~g} / \mathrm{dl}$ & $13.2 \mathrm{~g} / \mathrm{dl}$ & $16.0 \mathrm{~g} / \mathrm{dl}$ & \\
\hline Platelet count & $\begin{array}{l}97,000 / \mu l \\
(140,000-450,000 / \mu l)\end{array}$ & $130,000 / \mu l$ & $107,000 / \mu l$ & $118,000 / \mu l$ & \\
\hline ALT & $\begin{array}{l}42 \mathrm{U} / \mathrm{I} \\
(10-45 \mathrm{U} / \mathrm{I})\end{array}$ & $53 \mathrm{U} / \mathrm{I}$ & $23 \mathrm{U} / \mathrm{I}$ & $38 \mathrm{U} / \mathrm{I}$ & \\
\hline AST & $\begin{array}{l}50 \cup / I \\
(10-45 \cup / I)\end{array}$ & $39 \mathrm{U} / \mathrm{I}$ & $30 \mathrm{U} / \mathrm{I}$ & $69 \mathrm{U} / \mathrm{I}$ & \\
\hline Bilirubin total & $\begin{array}{l}1.06 \mathrm{mg} / \mathrm{dl} \\
(0-1.52 \mathrm{mg} / \mathrm{dl})\end{array}$ & $1.0 \mathrm{mg} / \mathrm{dl}$ & $0.33 \mathrm{mg} / \mathrm{dl}$ & $0.36 \mathrm{mg} / \mathrm{dl}$ & \\
\hline $\mathrm{LDH}$ & $\begin{array}{l}193 \mathrm{mg} / \mathrm{dl} \\
(135-225 \mathrm{mg} / \mathrm{dl})\end{array}$ & $350 \mathrm{mg} / \mathrm{dl}$ & $272 \mathrm{mg} / \mathrm{dl}$ & $319 \mathrm{mg} / \mathrm{dl}$ & \\
\hline CRP & $\begin{array}{l}8.3 \\
(0-5 \mathrm{mg} / \mathrm{l})\end{array}$ & $\begin{array}{l}21 \mathrm{mg} / \mathrm{l}, 109 \mathrm{mg} / \mathrm{l} \\
\text { (2nd visit) }\end{array}$ & $107 \mathrm{mg} / \mathrm{l}$ & $7.9 \mathrm{mg} / \mathrm{l}$ & \\
\hline Serum creatinine & $\begin{array}{l}1.65 \mathrm{mg} / \mathrm{dl} \\
(0.62-1.24 \mathrm{mg} / \mathrm{dl})\end{array}$ & $0.73 \mathrm{mg} / / \mathrm{dl}$ & $0.74 \mathrm{mg} / \mathrm{dl}$ & $0.84 \mathrm{mg} / \mathrm{dl}$ & \\
\hline Ferritin & $\begin{array}{l}1,332 \mu \mathrm{g} / \mathrm{l} \\
\text { (male } 30-400 \mu \mathrm{g} / \mathrm{l})\end{array}$ & $\begin{array}{l}1,462 \mu \mathrm{g} / \mathrm{l} \\
\text { (female 13-150 } \mu \mathrm{g} / \mathrm{l})\end{array}$ & $93 \mu \mathrm{g} / \mathrm{l}$ & $190 \mu \mathrm{g} / \mathrm{l}$ & \\
\hline Dengue IgG & Positive & Positive & Positive & Negative & \\
\hline Dengue lgM & Negative & Positive & Positive & Negative & \\
\hline Dengue Ns Ag & Positive & Negative & Positive & Positive & Table 1. Demographics and main \\
\hline Dengue PCR & Not detected & Detected & Not detected & Detected & patients \\
\hline
\end{tabular}

Thrombocytopenia is also common in patients with COVID-19 and is associated with severe disease and an increased risk of mortality: the lower the platelet count, the higher the mortality ${ }^{[7,8]}$.

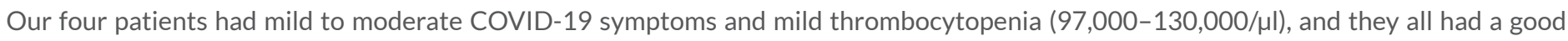
outcome.

A French medical team on Reunion Island in the Indian Ocean reported the first case of dengue fever and COVID-19 co-infection with a normal chest $\mathrm{CT}^{[9]}$.

According to the Centers for Disease Control and Prevention (CDC), laboratory confirmation of DF can be made from a single acute-phase serum specimen obtained early ( $\leq 7$ days after fever onset) in the illness through detection of viral genomic sequences with RT-PCR or dengue non-structural protein 1 (NS1) antigen by immunoassay. The presence of virus shown by RT-PCR or NS1 antigen in a single diagnostic specimen is considered laboratory confirmation of dengue in patients with a compatible clinical and travel history ${ }^{[10]}$.

Our first, third and fourth patients had positive NS1 antigen tests early during their febrile illness. The second and fourth patients both had positive RT-PCR tests for DF during the first week. 

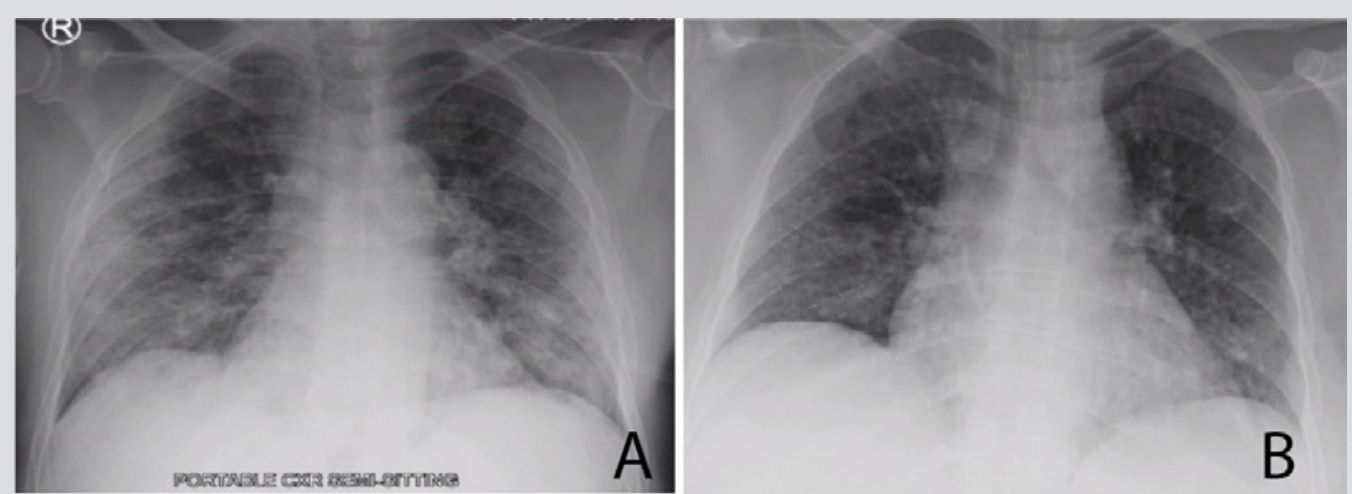

\section{(R)}

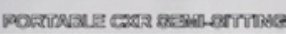

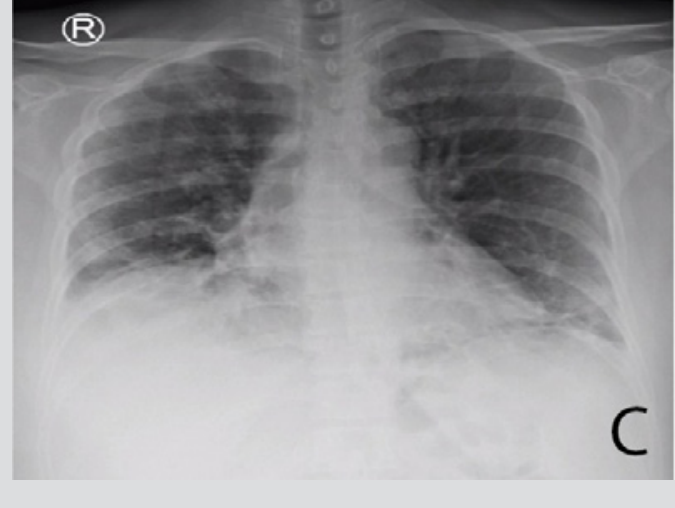

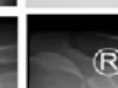

(B)

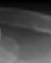
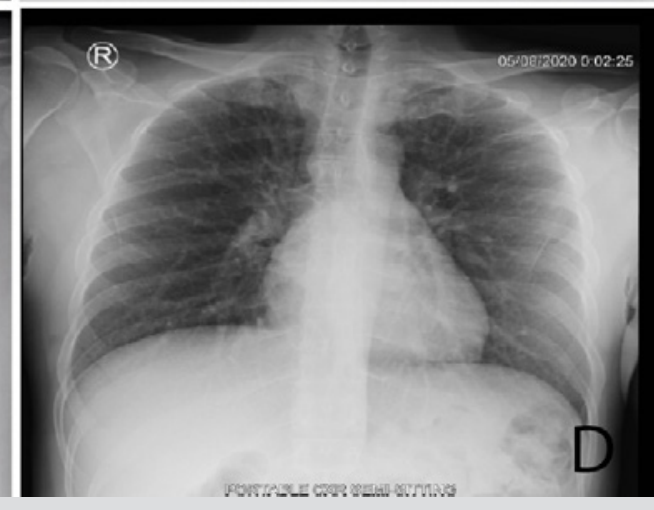

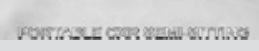

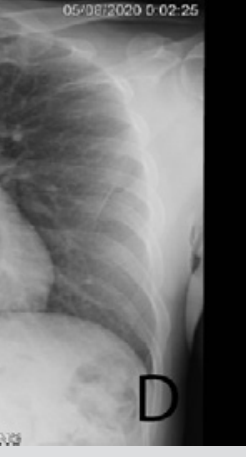

Figure 1. (a) Portable chest $x$-ray showing

bilateral peripheral airspace opacities more prominent at the lung bases. The findings are suggestive of viral chest infection, most probably COVID-19 infection. (b) Portable chest $x$-ray revealing bilateral basal areas of ground-glass appearance in early COVID-19 infection. (c) Portable chest $x$-ray showing bilateral peripheral and basal patchy airspace opacities. (d) Portable chest $x$-ray showing peripheral groundglass appearance more at the left base, most probably early organizing COVID-19 pneumonia

In an Indian study, the sensitivity, specificity, positive and negative predictive values of NS1 Ag detection ELISA were 73.5\%, 100\%, 100\% and $70 \%$, respectively, while for real-time RT-PCR they were $79.4 \%, 100 \%, 100 \%$ and $75 \%$, respectively. The maximum sensitivity of NS1 antigen was seen at 2 days of fever and that of real-time RT-PCR at 3 days of fever ${ }^{[11]}$.

The presence of both IgM and IgG in our second and third patients may have been due to secondary infection (i.e., previous DF infection), but both patients also had a good outcome.

\section{REFERENCES}

1. Lansbury L, Lim B, Baskaran V, Lim WS. Co-infections in people with COVID-19: a systematic review and meta-analysis. J Infect 2020;81(2):266-275.

2. Centers for Disease Control and Prevention. Dengue around the world. Available from https://www.cdc.gov/dengue/areaswithrisk/around-the-world.html (accessed 7 December 2020).

3. Babiker T, Rasitha Banu GM, Bashier I, Hajmeeral M. Incidence rate of dengue fever in Saudi Arabia 2011-2018, a retrospective. Int J Recent Technol Eng 2019;8(4S5).

4. Badreddine S, Al-Dhaheri F, Al-Dabbagh A, Al-Amoudi A, Al-Ammari M, Elatassi N, et al. Dengue fever. Clinical features of 567 consecutive patients admitted to a tertiary care center in Saudi Arabia. Saudi Med J 2017;38(10):1025-1033.

5. Azhar E, Kao M, Niedrig M, Masri B, Godus A, Badierah R. Virological diagnosis of dengue fever in Jeddah, Saudi Arabia: comparison between RT-PCR and virus isolation in cell culture. Infect Dis Immun 2010;2(2):24-29.

6. Hegazi MA, Bakarman MA, Alahmadi TS, Butt NS, Alqahtani AM, Aljedaani BS, et al. Risk factors and predictors of severe dengue in Saudi population in Jeddah, Western Saudi Arabia: a retrospective study. Am J Trop Med Hyg 2020;102(3):613-621.

7. Yang X, Yang Q, Wang Y, Wu Y, Xu J, Yu Y, et al. Thrombocytopenia and its association with mortality in patients with COVID-19. J Thromb Haemost 2020;18(6):1469-1472.

8. Lippi G, Plebani M, Henry BM. Thrombocytopenia is associated with severe coronavirus disease 2019 (COVID-19) infections: a meta-analysis. Clin Chim Acta 2020;506:145148.

9. Verduyn M, Allou N, Gazaille V, Andre M, Desroche T, Jaffar MC, et al. Co-infection of dengue and COVID-19: a case report. PLoS NegI Trop Dis 2020;14(8):e0008476.

10. Centers for Disease Control and Prevention. Dengue. Diagnosis. Available from https://www.cdc.gov/dengue/healthcare-providers/diagnosis (accessed 7 December 2020).

11. Ahmed NH, Broor S. Comparison of NS1 antigen detection ELISA, real time RT-PCR and virus isolation for rapid diagnosis of dengue infection in acute phase. $J$ Vector Borne Dis 2014;51(3):194199. 